\title{
Pengaruh Permainan Magic Card terhadap Kemampuan Bercerita Anak Usia Dini
}

\author{
Wendy Erste Sohn Chandra ${ }^{\varpi_{1}}$, Delfi Eliza $^{2}$ \\ Pendidikan Anak Usia Dini, Universitas Negeri Padang \\ DOI: $10.31004 /$ obsesi.v4i2.460
}

\begin{abstract}
Abstrak
Tujuan penelitian ini adalah mengetahui pengaruh permainan Magic Card terhadap kemampuan bercerita anak di PAUD Inklusi Istiqamah Islamic School Bukittinggi. Jenis penelitian yang digunakan adalah metode kuantitatif dengan jenis eksperimen atau penelitian quasi eksperimen dengan menggunakan Permainan Magic Card. Permainan Magic Card berpengaruh terhadap bercerita anak di PAUD inklusi Istiqamah Islamic School Bukittinggi. Berdasarkan analisis data, diperoleh nilai rata-rata hasil Kemampuan Bercerita anak di kelas eksperimen yang menggunakan Permainan Magic Card lebih tinggi (82) dibandingkan kelas kontrol yang menggunakan kartu gambar $(72,6)$ karena pembelajaran menggunakan permainan Magic Card memberikan gambaran konkrit berupa media 3 dimensi sehingga anak menemukan banyak hal yang akan diceritakan.
\end{abstract}

Kata Kunci: permainan magic card; kemampuan bercerita; anak.

\begin{abstract}
The purpose of this study was to determine the Effect of Magic Card Games on Children's Storytelling Ability in Istiqamah Islamic School Bukittinggi Inclusion PAUD. This type of research is a quantitative method with the type of experiment or quasi-experimental research using Magic Card Games. The Magic Card game affects children's storytelling at Istiqamah Islamic School Bukittinggi Inclusion PAUD. Based on data analysis, the average value of the results of the storytelling ability of children in the experimental class using Magic Card Games is higher (82) compared to the control class using picture cards (72.6) because learning using the Magic Card game gives a concrete picture in the form of 3-dimensional media so that children find many things to tell.
\end{abstract}

Keywords: magic card game; story ability; child

Copyright (c) 2020 Wendy Erste Sohn Chandra, Delfi Eliza

$\triangle$ Corresponding author :

Email Address : wendy.chandra2303@gmail.com (Padang, Sumatera Barat, Indonesia)

Received 6 February 2020, Accepted 10 February 2020, Published 15 February 2020 


\section{PENDAHULUAN}

Pendidikan anak usia dini merupakan salah satu bentuk fasilitas atau wadah untuk penanaman pondasi dasar sehingga seluruh aspek perkembangan anak harus distimulasi secara optimal. Pendidikan Anak Usia Dini (PAUD) adalah lembaga pendidikan untuk anak usia 0-6 tahun.Salah satu bentuk Pendidikan Anak Usia Dini (PAUD) pada jalur formal adalah Taman Kanak-kanak (TK). Anak usia dini di Taman Kanak-Kanak merupakan individu yang berada pada rentang usia 4 sampai 6 tahun. Pada usia ini merupakan masa keemasan atau golden age. Tujuan TK, yaitu untuk menstimulasi seluruh potensi anak dan mempersiapkan anak ke jenjang pendidikan selanjutnya serta menjadi wahana bagi anak untuk belajar bersosialisasi (Tatminingsih, 2019). Pertumbuhan dan perkembangan anak usia dini perlu diarahkan pada dasar-dasar yang tepat bagi pertumbuhan dan perkembangan manusia seutuhnya yaitu pertumbuhan dan perkembangan fisik, daya pikir, daya cipta, sosial emosional, bahasa dan komunikasi yang seimbang sebagai dasar pembentukan pribadi yang utuh (Ayu, 2016).

Bahasa merupakan salah satu aspek yang harus distimulasi pada anak usia dini. bahasa akan menjadi kemampuan yang dibutuhkan untuk mampu menyeuaikan diri sesuai dengan norma-norma yang ada di lingkungan masyarakat. Bahasa memiliki peran penting dalam perkembangan intelektual, sosial, dan emosional peserta didik dan merupakan penunjang keberhasilan dalam mempelajari semua bidang studi (Fajriah, 2015). Anak-anak menggunakan bahasa sebagai alat komunikasi dan media untuk mengungkapkan emosi baik positif ataupun emosi negatif(Yumi, Atmazaki and Gani, 2019). Kemampuan berbahasa bagi anak usia dini sangatlah penting, karena dengan kegiatan bercerita anak bisa mengungkapkan tentang kisah-kisah tertentu yang pernah dialaminya, serta perasaannya yang dialami kepada orang yang lebih dewasa (Wondal, 2019). Bahasa mempunyai peranan yang sangat penting bagi kehidupan manusia untuk berinteraksi dengan sesamanya, oleh karenanya perkembangan bahasa harus dirangsang sejak dini (Ngura, 2018). Pembelajaran bahasa pada anak usia dini meliputi mendengar, berbicara, membaca, dan menulis. Berbicara dengan bercerita mengartikan bahwa anak sedang mengembangkan perkembangan bahasanya, melatih anak dalam pembendaharaan kosakata sehingga lebih luas dalam mengenal bahasa dan mempersiapkan anak untuk melanjutkan ke tahap menulis dan membaca diakhiri dengan menyimak/mendengar (Ruiyat, Yufiarti and Karnadi, 2019).

Bercerita merupakan bentuk kemampuan berbicara dalam aspek bahasa. Anak yang senang bercerita akan memiliki banyak pembendaharaan kata. bercerita merupakan skill yang dimiliki oleh seorang anak untuk mengungkapkan perasaan melalui kata-kata dan ekspresi, sehingga anak dapat memberikan informasi kepada orang lain dan dapat memperkaya pembendaharaan kata anak (Rachmi, 2015). Selain itu anak akan terlatih berkomunikasi secara lisan dengan orang-orang yang ada di lingkungannya. Anak yang akan bercerita membuat kata-kata sendiri melalui gambar yang dilihat (Rizqiyani and Azizah, 2018). Menurut (Peraturan Menteri Pendidikan dan Kebudayaan Republik Indonesia No. 137, 2014) kemampuan mengungkapkan atau bercerita meliputi 1) Berkomunikasi secara lisan, memiliki perbendaharaan kata; 2) Menyusun kalimat sederhana dalam struktur lengkap (pokok kalimat predikat keterangan); 3) Memiliki lebih banyak kata-kata untuk mengekpresikan ide pada orang lain; 4) Melanjutkan sebagian cerita/dongeng yang telah diperdengarkan Menunjukkkan pemahaman konsep-konsep dalam buku cerita; 5) Menunjukkkan pemahaman konsep-konsep dalam buku cerita

Menurut NAEYC dalam (Rahmatika, Hartati and Yetti, 2019) buku cerita atau buku bergambar bukanlah satu-satunya media yang dapat digunakan pembelajaran bahasa untuk anak-anak. Oleh karena itu dapat digunakan media lainnya yaitu permainan Magic Card. Permainan Magic card berbeda dengan bentuk kartu lainnya. Magic Card merupakan bentuk modifikasi kartu menjadi bentuk 3 dimensi sehingga terlihat lebih nyata oleh anak sehingga pengalaman belajar anak lebih nyata dan konkrit. Magic Card menyediakan benda berbentuk 3 dimensi dalam kartu yang 2 dimensi. Magic Card didesain menggunakan kain flannel yang 
diisi dakron sehingga membentuk 3 dimensi. Setiap Magic Card akan didesain gambar yang menarik dan anak akan bercerita mengenai pengalaman atau khayalannya mengenai gambar tersebut. Penggunaan permainan magic card akan menstimulasi anak untuk bercerita dan memberikan informasi tentang gambar yang lebih konkrit pada permainan magic card sehingga anak terlatih dalam menyusun kalimat.

Tabel 1. Data Awal Kemampuan Bercerita Anak PAUD Inklusi Istiqamah Islamic School Bukittinggi

\begin{tabular}{clcccc}
\hline No & \multicolumn{1}{c}{ Indikator } & BB & MB & BSH & BSB \\
\hline 1 & $\begin{array}{l}\text { Menyusun kalimat } \\
\text { sederhana }\end{array}$ & 5 & 7 & 3 & 0 \\
2 & $\begin{array}{l}\text { Menceritakan } \\
\text { pengalaman/kejadian } \\
\text { secara sederhana }\end{array}$ & 6 & 7 & 2 & 0 \\
3 & $\begin{array}{l}\text { Memberikan } \\
\text { keterangan/informasi } \\
\text { tentang suatu hal }\end{array}$ & 6 & 7 & 2 & 0 \\
mber: PAUD Inklusi Istiqamah Islamic School Kelompok B 2020)
\end{tabular}

Keterangan:

BB : Belum Berkembang

MB : Mulai Berkembang

BSH : Berkembang Sesuai Harapan

BSB : Berkembang Sangat Baik

Berdasarkan observasi kemampuan awal membaca anak lebih dari 50\% anak belum mampu bercerita seperti anak masih ragu dan tidak sempurna dalam menyusun kalimat. Selain itu anak juga belum mampu menceritakan pengalaman pribadi atau memberikan informasi sehingga seringkali pengalaman yang diceritakan anak belum menjadi suatu cerita yang mudah dipahami sehingga menyebabkan hilangnya rasa percaya diri anak dalam bercerita dan berinteraksi dengan lingkungannya.

\section{METODOLOGI}

Penelitian ini menggunakan pendekatan kuantitatif. Penelitian ini menggunakan metode quasy exsperiment (eksperimen semu). Sumber data dalam penelitian ini adalah kelas eksperimen berjumlah 15 orang dan kelas kontrol berjumlah 15 orang di Taman Kanakkanak PAUD Inklusi Istiqamah Islamic School Bukittinggi. Teknik pengumpulan data melalui observasi dan dokumentasi. Pada penelitian ini terdapat dua kelompok yaitu kelompok eksperimen dan kelompok kontrol. Kelompok eksperimen dilakukan pembelajaran menggunakan permainan magic card sedangkan kelompok kontrol mendapatkan pembelajaran dengan kartu gambar. Kemudian dilakukan pretest dan posttest terhadap kedua kelompok untuk melihat pengaruh permainan magic card terhadap kemampuan bercerita anak yang digambarkan pada alur berikut: 


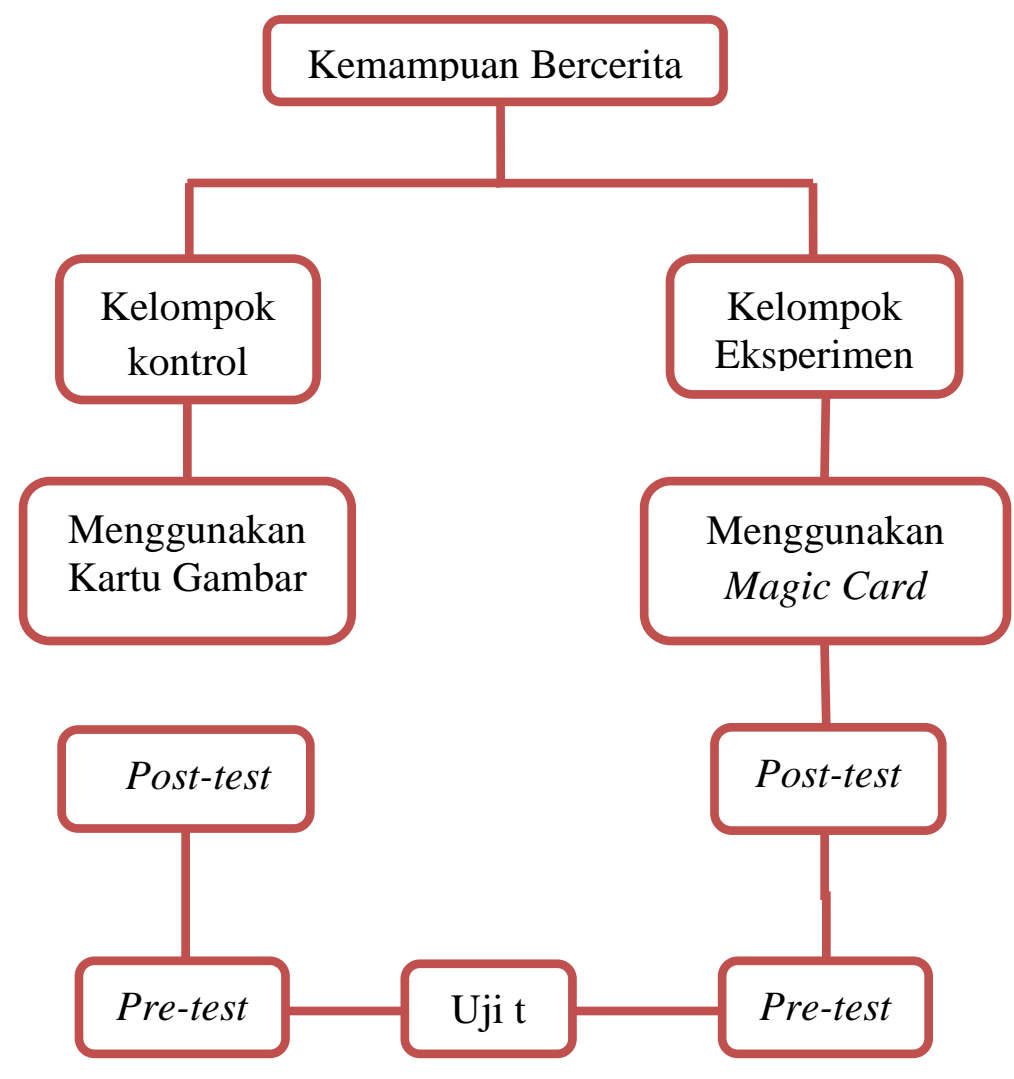

Bagan 1. Alur Penelitian

\section{HASIL DAN PEMBAHASAN}

Setelah dilakukan penelitian ditemukan bahwa nilai Pretest Kemampuan Bercerita Anak Kelas Eksperimen dan Kelas Kontrol. Berikut data hasil nilai Pretest Kemampuan Bercerita Anak Kelas Eksperimen dan Kelas Kontrol.

Tabel 2. Nilai Pre-test Kemampuan Bercerita Anak Kelas Eksperimen dan Kelas Kontrol

\begin{tabular}{cccccc}
\hline No & Nama & Kelas Eksperimen & No & Nama & Kelas Kontrol \\
\hline 1 & X1 & 50 & 1 & Y1 & 50 \\
2 & X2 & 50 & 2 & Y2 & 50 \\
3 & X3 & 55 & 3 & Y3 & 55 \\
4 & X4 & 60 & 4 & Y4 & 55 \\
5 & X5 & 60 & 5 & Y5 & 55 \\
6 & X6 & 60 & 6 & Y6 & 55 \\
7 & X7 & 65 & 7 & Y7 & 60 \\
8 & X8 & 65 & 8 & Y8 & 60 \\
9 & X9 & 65 & 9 & Y9 & 60 \\
10 & X10 & 65 & 10 & Y10 & 60 \\
11 & X11 & 65 & 11 & Y11 & 65 \\
12 & X12 & 70 & 12 & Y12 & 65 \\
13 & X13 & 70 & 13 & Y13 & 65 \\
14 & X14 & 70 & 14 & Y14 & 65 \\
15 & X15 & 70 & 15 & Y15 & 65 \\
\hline
\end{tabular}

Hasil pre-test terlihat bahwa rata-rata kelas eksperimen yaitu 62,6 dan rata-rata kelas kontrol yaitu 59. Untuk menarik kesimpulan dari hasil penelitian, dilakukan uji hipotesis Dengan menggunakan uji $t$. Sebelum melakukan uji $t$ terlebih dahulu dilakukan uji normalitas dan uji homogenitas terhadap hasil penelitian. 
Tabel 3.Hasil Perhitungan Pengujian Liliefors Pre-test Kelompok Eksperimen dan Kelompok Kontrol

\begin{tabular}{clccccc}
\hline No & Kelompok & $\mathbf{N}$ & $\alpha$ & $\mathbf{L}_{\text {hitung }}$ & $\mathbf{L}_{\text {tabel }}$ & Keterangan \\
\hline 1 & Eksperimen & 15 & 0,05 & 0,1292 & 0,220 & Normal \\
2 & Kontrol & 15 & 0,05 & 0,1271 & 0,220 & Normal
\end{tabular}

Berdasarkan tabel 3 terlihat bahwa kelompok eksperimen nilai $L_{\text {hitung }} \mathbf{0 , 1 2 9 2}$ lebih kecil dari $L_{\text {tabel }} \mathbf{0 , 2 2 0}$ untuk $\alpha$ 0,05. Dengan demikian nilai kelompok eksperimen berasal dari data yang berdistribusi normal. Untuk kelompok kontrol diperoleh $L_{\text {hitung }} \mathbf{0 , 1 2 7 1}$ lebih kecil dari $L_{\text {tabee }} \mathbf{0 , 2 2 0}$ untuk $\alpha$ 0,05. Ini berarti bahwa data kelompok kontrol berasal dari data yang berdistribusi normal.

Tabel 4.Hasil Perhitungan Uji Homogenitas Pre-test Kelas Eksperimen dan Kelas Kontrol

\begin{tabular}{ccccc}
\hline Kelas & $\mathrm{A}$ & $\begin{array}{c}\chi^{2} \\
\text { hitung }\end{array}$ & $\begin{array}{c}\chi^{2} \\
\text { table }\end{array}$ & Kesimpulan \\
\hline $\begin{array}{c}\text { Eksperimen } \\
\text { Kontrol }\end{array}$ & 0,05 & 0,695 & 3,841 & Homogen \\
\hline
\end{tabular}

Berdasarkan Tabel 4 tampak bahwa $\chi^{2}$ hitung kelompok eksperimen dan kelompok

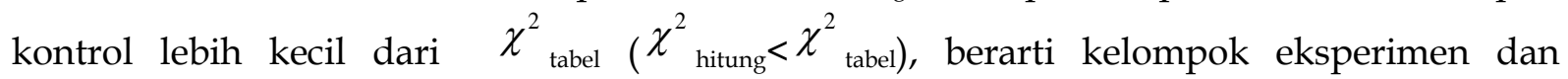
kelompok kontrol memiliki varians yang homogen. Setelah dilakukan uji normalitas dan uji homogenitas, diketahui bahwa kedua kelas sampel berdistribusi normal dan mempunyai varians homogen. Maka dapat dilanjutkan dengan pengujian hipotesis dengan menggunakan teknik t-tes.

Tabel 5. Hasil Perhitungan Nilai Pre-test Kelompok Eksperimen dan Kelompok Kontrol

\begin{tabular}{ccc}
\hline Aspek & Kelompok Eksperimen & Kelompok Kontrol \\
\hline $\mathrm{N}$ & 15 & 15 \\
$\bar{X}$ & 62,6 & 59 \\
\hline
\end{tabular}

Tabel 6. Hasil Perhitungan Pre-test Pengujian dengan $t$-test

\begin{tabular}{ccccccc}
\hline No & Kelompok & $\mathbf{N}$ & $\begin{array}{c}\text { Hasil } \\
\text { Rata-rata }\end{array}$ & thitung & $\begin{array}{c}t_{\text {tabel }} \\
\mathbf{a ~ 0 , 0 5}\end{array}$ & Keputusan \\
\hline $\mathbf{1}$ & Eksperimen & 15 & 62,6 & 1,614 & 2,048 & Terima $\mathrm{H}_{\mathbf{0}}$ \\
$\mathbf{2}$ & Kontrol & 15 & 59 & &
\end{tabular}

$\mathrm{T}$ tabel untuk taraf nyata $\mathrm{a}=0,05(5 \%)$ dengan $\mathrm{df}$ sebesar 28 adalah $=\mathbf{2 , 0 4 8}$ Dengan demikian, dapat diketahui bahwa pada taraf nyata $a=0,05(5 \%), \mathbf{t}_{\text {hitunglebih kecil dari pada }}$ $\mathbf{t}_{\text {tabel }}(\mathbf{1}, \mathbf{6 1 4}<\mathbf{2 , 0 4 8})$. Jadi, dapat disimpulkan bahwa tidak terdapat perbedaan yang signifikan antara hasil pre-test (kemampuan awal) Kemampuan Bercerita anak di kelompok eksperimen dengan kelompok kontrol di PAUD Inklusi Istiqamah Islamic School Bukittinggi. 
Tabel 7. Nilai Post-test Kemampuan Bercerita Anak Kelas Eksperimen dan Kelas Kontrol

\begin{tabular}{cccccc}
\hline No & Nama & Kelas Eksperimen & No & Nama & Kelas Kontrol \\
\hline 1 & X1 & 75 & 1 & Y1 & 65 \\
2 & X2 & 75 & 2 & Y2 & 65 \\
3 & X3 & 75 & 3 & Y3 & 65 \\
4 & X4 & 75 & 4 & Y4 & 70 \\
5 & X5 & 80 & 5 & Y5 & 70 \\
6 & X6 & 80 & 6 & Y6 & 70 \\
7 & X7 & 80 & 7 & Y7 & 70 \\
8 & X8 & 80 & 8 & Y8 & 75 \\
9 & X9 & 85 & 9 & Y9 & 75 \\
10 & X10 & 85 & 10 & Y10 & 75 \\
11 & X11 & 85 & 11 & Y11 & 75 \\
12 & X12 & 85 & 12 & Y12 & 75 \\
13 & X13 & 90 & 13 & Y13 & 80 \\
14 & X14 & 90 & 14 & Y14 & 80 \\
15 & X15 & 90 & 15 & Y15 & 80
\end{tabular}

Hasil Post test terlihat bahwa kelas eksperimen rata-rata 82 sedangkan pada kelas kontrol memperoleh rata-rata 72,6. Uji normalitas kelas eksperimen dan kelas control diperoleh harga $\mathrm{L}_{0}$ dan $\mathrm{L}_{1}$ pada taraf nyata 0,05 untuk $\mathrm{N}=15$ seperti pada tabel:

Tabel 8. Hasil Perhitungan Pengujian Liliefors Post-test Kelompok Eksperimen dan Kelompok Kontrol

\begin{tabular}{clccccc}
\hline No & Kelompok & $\mathbf{N}$ & $\mathbf{A}$ & $\mathbf{L}_{\mathbf{0}}$ & $\mathbf{L}_{\mathbf{t}}$ & Keterangan \\
\hline 1 & Eksperimen & 15 & 0,05 & 0,1706 & 0,220 & Normal \\
2 & Kontrol & 15 & 0,05 & 0,1515 & 0,220 & Normal \\
\hline
\end{tabular}

Hasil tabel 8 terlihat bahwa kelompok eksperimen nilai $L$ hitung 0,1706 lebih kecil dari $L$ tabel 0,220 untuk $\alpha$ 0,05. Dengan demikian nilai kelompok eksperimen berasal dari data yang berdistribusi normal. Untuk kelompok kontrol diperoleh $L$ hitung 0,1515 lebih kecil dari $L$ tabel $\mathbf{0 , 2 2 0}$ untuk $\alpha$ 0,05. Ini berarti bahwa data kelompok kontrol berasal dari data yang berdistribusi normal.

Tabel 9. Hasil Uji Homogenitas Post-test Kelompok Eksperimen dan Kelompok Kontrol

\begin{tabular}{ccccc}
\hline Kelompok & $a$ & $\chi_{\text {hitung }}^{2}$ & $\chi_{\text {table }}^{2}$ & Kesimpulan \\
\hline $\begin{array}{c}\text { Eksperimen } \\
\text { Kontrol }\end{array}$ & 0,05 & 0,3478 & 3,841 & Homogen \\
\hline
\end{tabular}

Berdasarkan Tabel 9 tampak bahwa $\chi^{2}$ hitung kelompok eksperimen dan kelompok

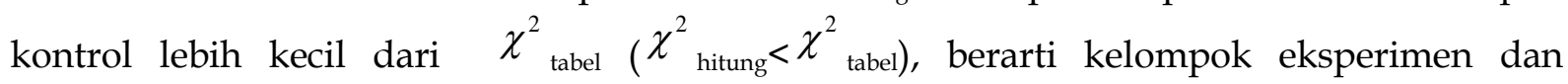
kelompok kontrol memiliki varians yang homogen.

Tabel 10. Hasil Perhitungan Post-test Pengujian Dengan $t$-test

\begin{tabular}{ccccccc}
\hline No & Kelompok & $\mathbf{N}$ & HasilRata-rata & $\mathbf{t}$ hitung & $\mathbf{t}$ tablea 0,05 & Keputusan \\
\hline $\mathbf{1}$ & Eksperimen & 15 & 82 & 4,723 & 2,048 & Tolak $\mathrm{H}_{0}$ \\
$\mathbf{2}$ & Kontrol & 15 & 72,6 & & \\
\hline
\end{tabular}


Perbandingan hasil perhitungan nilai pre-test dan post test terlihat pada nilai tertinggi dan nilai terendah yang diperoleh anak dan terlihat pada rata-rata kelas eksperimen dan kelas kontrol pada post-test dimana pada post-test rata-rata menjadi lebih meningkat dari rata-rata pre-test setelah dilakukan treatment.

Untuk lebih jelasnya dapat dilihat pada grafik 1.

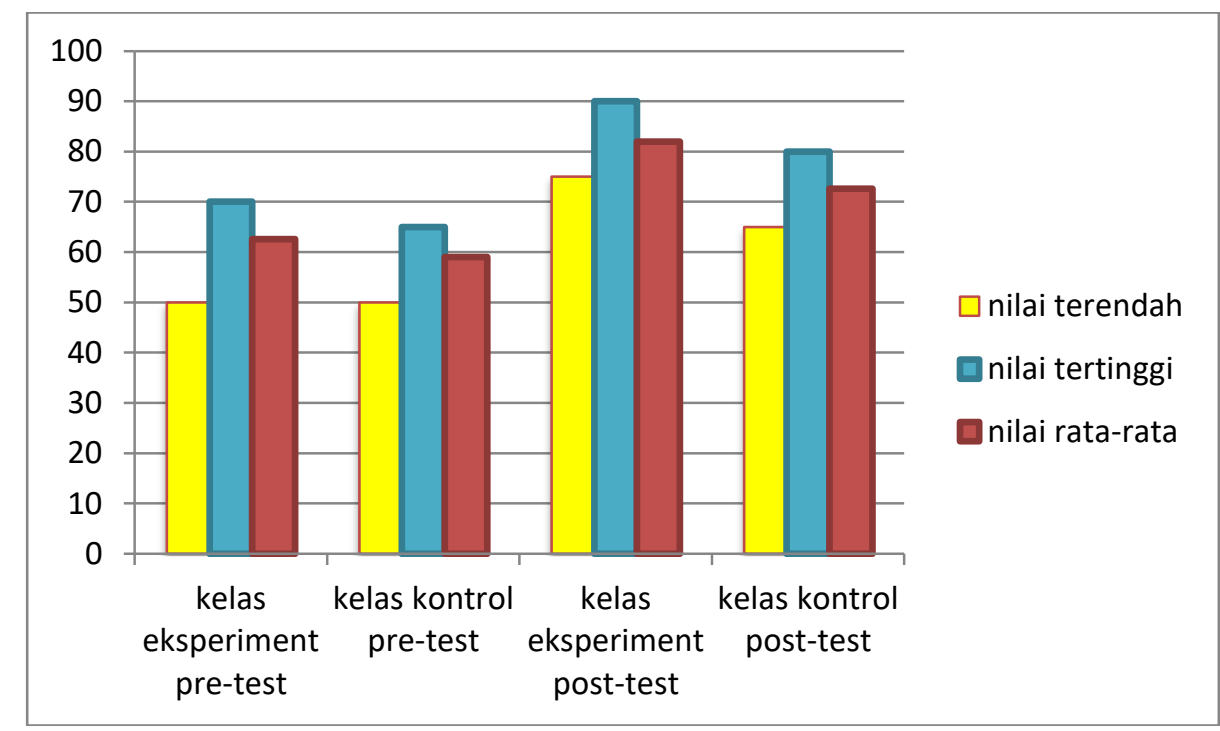

\section{Grafik 1.Data Perbandingan Hasil Pre-Test dan Post-Test Kemampuan Bercerita Anak Eksperimen dan Kelompok Kontrol}

Dari penelitian yang peneliti lakukan terlihat hubungan hasil pre-test dan post-test. Hasil pre-test terlihat bahwa rata-rata kelas eksperimen yaitu 62,6 dan rata-rata kelas kontrol yaitu 59. Setelah diberikan treatment terlihat hasil post-test Kemampuan Bercerita pada kelas eksperimen menggunakan Permainan Magic Card lebih meningkat dengan rata-rata 82 sedangkan pada kelas kontrol menggunakan kartu gambar memperoleh rata-rata 72,6. Dapat disimpulkan bahwa terdapat perbandingan hasil pre-test dan hasil post-test Kemampuan Bercerita kelompok eksperimen dan kelompok kontrol. Dengan demikian terbukti Permainan Magic Card berpengaruh terhadap Kemampuan Bercerita Anak di PAUD Inklusi Istiqamah Islamic School Bukittinggi.

Secara intelektual, perkembangan anak berbeda-beda, baik intelegensi, bakat, minat, kreativitas, kematangan emosi, kepribadian, kemandirian jasmani dan sosialnya (Astuti and Aziz, 2019). Setiap anak diciptakan Tuhan sebagai individu yang unik karena setiap anak memiliki pola perkembangan yang berbeda satu dengan yang lain (Anggraeni, Hartati and Nurani, 2019). Anak usia dini merupakan individu yang membutuhkan perhatian dalam tumbuhkembangnya. Anak usia dini merupakan dasar awal yang menentukan kehidupan suatu bangsa dimasa yang akan datang (Anhusadar and Islamiyah, 2019). Pada usia ini pula anak akan merespons serta mengolah berbagai hal yang diterimanya dengan cepat(Inten and Permatasari, 2019). Anak usia dini berada pada tahap golden age periode kehidupan manusia (Islamiah, Fridani and Supena, 2019). Anak usia dini adalah sosok individu sebagai makhluk sosiokultural yang sedang mengalami proses perkembangan yang sangat fundemental bagi kehidupan selanjutnya dan memiliki sejumlah karakteristik tertentu (Suryana, 2013). Disimpulkan bahwa anak usia dini merupakan individu yang membutuhkan stimulasi dalam proses pertumbuhan dan perkembangan dalam berbagai aspek.

Setiap anak membutuhkan pendidikan untuk perkembangan dan hidup dengan baik di lingkungan masyarakat. Pendidikan berperan penting untuk membentuk pola pikir (Yunita, Meilanie and Fahrurrozi, 2019). PAUD memiliki makna yang paling tinggi dari satuan-satuan pendidikan lainnya karena akan melandasi pendidikan dasar, pendidikan menengah, dan pendidikan tinggi (Wati, 2016). (Sudarna, 2014) mengemukakan bahwa 
pendidikan anak usia dini adalah suatu proses pembinaan tumbuh kembang anak sejak lahir sampai usia 6 tahun, yang dilakukan secara menyeluruh, mencakup semua aspek perkembangan dengan memberikan stilmulasi terhadap perkembangan jasmani dan rohani agar anak dapat tumbuh dan berkembang secara optimal. Berdasarkan uraian tersebut disimpulkan bahwa Pendidikan Anak Usia Dini merupakan sarana yang memberikan pengalaman berupa pengetahuan bagi anak. Menurut (Suhartini and Laela, 2018) PAUD bertujuan membimbing dan mengembangkan potensi setiap anak agar dapat berkembang potensi setiap anak agar dapat berkembang secara optimal sesuai tipe kecerdasannya. Menurut (Suyadi and Ulfah, 2013) karakteristik pendidikan anak usia dini yaitu:1) Mengutamakan kebutuhan anak; 2) Bermain sambil belajar, belajar seraya bermain; 3) Lingkungan yang kondusif dan matang; 4) Menggunakan pembelajar terpadu dalam bermain; 5) Mengembangkan berbagai kecakapan hidup atau keterampilan hidup (life skills); 6) Menggunakan berbagai media atau permainan edukatif dan sumber belajar; 7) Dilaksanakan secara bertahap dan berulang-ulang. (Suprapti, 2016)(Suprapti, 2016)(Suprapti, 2016)(Suprapti, 2016)(Suprapti, 2016)(Suprapti, 2016) mengatakan bahwa manfaat pendidikan anak usia dini untuk membina, dan menumbuh kembangkan seluruh potensi anak secara optimal, agar terbentuk perilaku dan kemampuan dasar yang selaras, serasi dan seimbang dengan tahap perkembangannya sehinggga memiliki kesiapan untuk memasuki pendidikan selanjutnya dalam mewujudkan tujuan pendidikan nasional.

Bahasa merupakan bagian terpenting dalam perkembangan anak. Bahasa seringkali dikaitkan dengan verbal (suara) dan non verbal (bahasa tubuh). Bahasa merupakan alat komunikasi yang diperoleh manusia sejak lahir(Suardi, Ramadhan and Asri, 2019). Bahasa merupakan alat komunikasi yang sangat penting dalam kehidupan manusia, karena merupakan alat untuk memahami perasaan kepada orang lain juga sebagai alat untuk memahami pikiran orang lain (Wondal, 2019). Vigotsky dalam (Susanto, 2011) menyatakan bahwa bahasa merupakan alat untuk mengekspresikan ide dan bertanya, dan bahasa juga menghasilkan konsep dan kategori-kategori untuk berpikir. Menurut (Susanto, 2011) fungsi pengembangan kemampuan berbahasa bagi anak taman kanak-kanak antara lain: 1) sebagai alat untuk berkomunikasi dengan lingkungan; 2) sebagai alat untuk mengembangkan kemampuan intelektual anak; 3) sebagai alat untuk mengembangkan ekspresi anak; dan 4) sebagai alat untuk menyatakan perasaan dan buah pikiran kepada orang lain. Kemampuan berbahasa terdiri dari mendengar, berbicara, membaca, dan menulis (Lestari, 2018). Beberapa aspek tersebut sangat dibutuhkan sehingga harus dikembangkan dalam proses pembelajaran anak usia dini.

Bercerita adalah proses komunikasi yang terjadi antara pencerita dengan pendengar cerita (Mulyatno, Sujana and Hafidah, 2018). Pendidikan anak usia dini tidaklah lepas dari kegiatan bercerita (Rizqiyani and Azizah, 2018). Bercerita adalah menuturkan sesuatu yang mengisahkan tentang perbuatan atau sesuatu kejadian dan disampaikan secara lisan dengan tujuan membagikan pengalamannya (Rizqiyani and Azizah, 2018). Bercerita juga mampu membantu anak untuk lebih berani mengungkapkan bahasa sehingga anak akan memperbanyak perbendaharaan kosakata (Sari, Sasmiati and Riswandi, 2019). Bercerita bagi seorang anak adalah sesuatu yang menyenangkan melalui cerita anak dapat mengembangkan imajinasinya menjadi apapun yang diinginkan (Fauziddin, 2017). Isjoni dalam (Niarni, 2018) bercerita mempunyai makna penting bagi perkembangan anak prasekolah/kelompok bermain, karena melalui bercerita kita dapat mengkomunikasikan nilai-nilai budaya, mengkomunikasikan nilai-nilai sosial, mengkomunikasikan nilai-nilai keagamaan, menanamkan etos kerja, etos waktu, etos alam, membantu mengembangkan fantasi anak, membantu mengembangkan dimensi kognitif anak, membantu mengembangkan dimensi bahasa anak.

Card berasal dari bahasa inggris yang berarti Kartu. Flash card adalah media pembelajaran visual yang berisi kata-kata, gambar, atau kombinasinya (Salmiati and Samsuri, 2018)Media kartu bergambar atau flashcard merupakan media kartu yang berisi 
gambar, di mana gambarnya dapat berasal dari buatan sendiri atau gambar/foto yang sudah ada dan digunakan untuk memudahkan siswa saat proses belajar. Sedangkan menurut Susilana dan Cepiriyana dalam (Wirman et al., 2018) menjelaskan bahwa card karena memiliki dua sisi maka pendidik bisa memanfaatkan kedua sisinya. Media flashcard memiliki kelebihan karena sederhana, mudah dibawa, juga bisa dimodifikasi. Magic Card merupakan bentuk modifikasi kartu menjadi bentuk 3 dimensi sehingga terlihat lebih nyata oleh anak sehingga pengalaman belajar anak lebih nyata dan konkrit. Magic Card menyediakan benda berbentuk 3 dimensi dalam kartu yang memiliki 2 dimensi. Magic Card didesain menggunakan kain flannel yang diisi dakron sehingga berbentuk 3 dimensi. Setiap Magic Card akan didesain gambar yang menarik dan anak akan bercerita mengenai pengalaman atau khayalannya mengenai gambar tersebut. Penggunaan permainan magic card akan menstimulasi anak untuk bercerita dan memberikan informasi tentang gambar yang lebih konkrit pada permainan magic card sehingga anak terlatih dalam menyusun kalimat. Selain itu media yang didesain dengan berbagai warna akan mengembangkan kemampuan kognitif anak seperti warna, ukuran gambar dan lainnya sehingga anak mampu memberikan informasi tentang gambar pada permainan Magic Card.

\section{SIMPULAN}

Penggunaan Permainan Magic Card dapat mengembangkan kemampuan bercerita anak karena pembelajaran menggunakan permainan Magic Card memberikan gambaran konkrit berupa media 3 dimensi sehingga anak menemukan lebih banyak hal yang akan diceritakan. Selain itu media yang digunakan lebih tahan lama daripada media kartu atau kertas sehingga bisa digunakan dalam jangka waktu yang lama. Namun dalam mendesain dibutuhkan waktu yang lama sehingga penggunaan Permainan Magic Card terbatas atau tidak bisa untuk semua tema. Diharapkan kepada guru di PAUD Inklusi Istiqamah Islamic School Bukittinggi hendaknya menerapkan Permainan Magic Card untuk mengembangkan Kemampuan Bercerita anak usia dini.

\section{UCAPAN TERIMAKASIH}

Penulis ucapkan terima kasih kepada koordinator dan dosen Program Studi PAUD fakultas ilmu pendidikan Universitas Negeri Padang yang memberikan masukan dan solusi dalam penulisan artikel ini serta keluarga dan teman-teman yang telah memberikan dukungan kepada penulis dalam menulis artikel ini.

\section{DAFTAR PUSTAKA}

Anggraeni, D., Hartati, S. and Nurani, Y. (2019) 'Implementasi Metode Bercerita dan Harga Diri dalam Meningkatkan Kemampuan Berbicara Anak Usia Dini', Jurnal Obsesi : Jurnal Pendidikan Anak Usia Dini, 3(2), p. 404. doi: 10.31004/obsesi.v3i2.224.

Anhusadar, L. O. and Islamiyah, I. (2019) 'Taman Layak Anak Usia Dini di Kota Kendari', Jurnal Obsesi : Jurnal Pendidikan Anak Usia Dini, 3(1), p. 117. doi: 10.31004/obsesi.v3i1.143.

Astuti, R. and Aziz, T. (2019) 'Integrasi Pengembangan Kreativitas Anak Usia Dini di TK Kanisius Sorowajan Yogyakarta', Jurnal Obsesi : Jurnal Pendidikan Anak Usia Dini, 3(2), p. 294. doi: 10.31004/obsesi.v3i2.99.

Ayu, C. (2016) 'Meningkatkan Kemampuan Kognitif Anak dalam Kegiatan Membilang dengan Metode Bermain Media Kartu Angka pada Anak Usia 4-5 Tahun di TK Taqifa Bangkinang', Jurnal PAUD Tambusai, 2(2), pp. 60-71.

Fajriah, Z. (2015) 'Peningkatan Penguasaan Kosakata Bahasa Arab (Mufradat) Melalui Penggunaan Media Kartu Kata Bergambar ( Penelitian Tindakan Pada Siswa kelas I MI Nurul Hakim Kediri Lombok Barat Tahun 2015 )', Jurnal Pendidikan Anak Usia Dini, 9(1), pp. 107-126. doi: 10.1109/MRA.2014.2360283. 
Fauziddin, M. (2017) ‘Upaya Peningkatan Kemampuan Bahasa Anak Usia 4-5 Tahun melalui Kegiatan Menceritakan Kembali Isi Cerita di Kelompok Bermain Aisyiyah Gobah Kecamatan Tambang', Jurnal Obsesi: Jurnal Pendidikan Anak Usia Dini, 1(1), pp. 42-51.

Inten, D. N. and Permatasari, A. N. (2019) 'Literasi Kesehatan pada Anak Usia Dini melalui Kegiatan Eating Clean', Jurnal Obsesi : Jurnal Pendidikan Anak Usia Dini, 3(2), p. 366. doi: 10.31004/obsesi.v3i2.188.

Islamiah, F., Fridani, L. and Supena, A. (2019) 'Konsep Pendidikan Hafidz Qur'an pada Anak Usia Dini', Jurnal Obsesi : Jurnal Pendidikan Anak Usia Dini, 3(1), p. 30. doi: 10.31004/obsesi.v3i1.132.

Lestari, I. (2018) 'Analisis Awal Kemampuan Bercerita pada Anak Usia 5-6 Tahun', Jurnal Ilmiah VISI PGTK PAUD dan Dikmas, 13(2), pp. 165-177.

Mulyatno, M. L., Sujana, Y. and Hafidah, R. (2018) ‘Penerapan Metode Mind Map untuk Meningkatkan Kemampuan Bercerita pada Anak Kelompok B 2 TK Al-Fatah Karanganyar Tahun Ajaran 2015/2016', Kumara Cendekia, 6(3), pp. 1-8.

Ngura, E. T. (2018) 'Pengembangan Media Buku Cerita Bergambar untuk Anak Usia Dini di TK Maria Virgo Kabupaten Ende', Jurnal Ilmiah Pendidikan Citra Bakti, 5(1), pp. 6-14.

'Peraturan Menteri Pendidikan dan Kebudayaan Republik Indonesia No. 137' (2014).

Rachmi, T. (2015) 'Pengaruh Permainan dan Kemampuan Menyimak terhadap Kemampuan Bercerita', Jurnal Pendidikan Anak Usia Dini, 9(1), pp. 127-142.

Rahmatika, P., Hartati, S. and Yetti, E. (2019) 'Metode Pembelajaran Mind Map dan Bercerita dengan Gaya Kognitif, Pengaruhnya terhadap Kemampuan Membaca Permulaan', Jurnal Obsesi : Jurnal Pendidikan Anak Usia Dini, 3(2), p. 548. doi: 10.31004/obsesi.v3i2.260.

Rizqiyani, R. and Azizah, N. (2018) 'Kemampuan Bercerita Anak Prasekolah (5-6 tahun)', PEMBELAJAR: Jurnal Ilmu Pendidikan, Keguruan, dan Pembelajaran, 2(2), p. 116. doi: 10.26858/ pembelajar.v2i2.6362.

Ruiyat, S. A., Yufiarti, Y. and Karnadi, K. (2019) 'Peningkatan Keterampilan Berbicara dengan Bercerita Menggunakan Komik Elektronik Tematik', Jurnal Obsesi : Jurnal Pendidikan Anak Usia Dini, 3(2), p. 518. doi: 10.31004/obsesi.v3i2.256.

Salmiati and Samsuri (2018) 'Penerapan Media Flash Card dalam Meningkatkan Kemampuan Membaca Permulaan pada Anak Kelompok A PAUD di Kabupaten Aceh Besar', Jurnal Buah Hati, 5(2), pp. 118-126.

Sari, I. P., Sasmiati and Riswandi (2019) 'Hubungan Penggunaan Media Alam dengan Kemampuan Bercerita Anak Usia Dini', Jurnal PG-PAUD, 5(1), pp. 1-8.

Suardi, I. P., Ramadhan, S. and Asri, Y. (2019) 'Pemerolehan Bahasa Pertama pada Anak Usia Dini', Jurnal Obsesi: Jurnal Pendidikan Anak Usia Dini, 3(1), p. 265. doi: 10.31004/obsesi.v3i1.160.

Sudarna (2014) 'Pendidikan Anak Usia Dini Berkarakter', Yogyakarta: Perpustakaan Nasional RI.

Suhartini, Y. and Laela, A. (2018) 'Meningkatkan Kecerdasan Natural Anak Usia Dini melalui Pengenalan Hewan di TK Pelita Kota Bandung', 2.

Suprapti, E. (2016) 'Peningkatan Pembelajaran Matetika Anak Usia Dini dengan Microsoft Powerpoint Ispring pada Materi Pengenalan Konsep Bilangan', Jurnal Pedagogi, 2(1), pp. 27-33.

Suryana, D. (2013) ‘Pendidikan Anak Usia Dini. Padang', UNP Press:Padang.

Susanto, A. (2011) ‘Perkembangan Anak Usia Dini', Jakarta: Kencana Prenada Media Group.

Suyadi and Ulfah, M. (2013) 'Konsep Dasar PAUD', Bandung: PT Remaja Rosdakarya.

Tatminingsih, S. (2019) 'Kemampuan Sosial Emosional Anak Usia Dini di Nusa Tenggara Barat', Jurnal Obsesi: Jurnal Pendidikan Anak Usia Dini, 3(2), p. 484. doi: 10.31004/obsesi.v3i2.170.

Wati, R. (2016) 'Upaya Meningkatkan Perhatian Anak Melalui Metode Bercerita dengan Media Boneka Tangan pada Anak Kelompok B TK Nurul Ibadah Kota Jambi', Jurnal 
Ilimiah Dikdaya, 9(1), pp. 114-123.

Wirman, A. et al. (2018) 'Penggunaan Media Moving Flash Card untuk Stimulasi Kemampuan Literasi Anak Usia Dini', Early Childhood: Jurnal Pendidikan, 2(2b), pp. 54-62. doi: 10.35568/earlychildhood.v2i2b.290.

Wondal, R. (2019) ‘Meningkatkan Kemampuan Bercerita Anak Melalui Metode Karya Wisata (Penelitian Tindakan Kelas pada Siswa Kelompok B TK Charis Kota Ternate Tahun Ajaran 2014/2015)', Pendidikan Anak Usia Dini, 9(1), pp. 1-14. doi: DOI: https:// doi.org/10.21009/JPUD.091DOI: https:// doi.org/10.21009/JPUD.091.01.

Yumi, M., Atmazaki, A. and Gani, E. (2019) ‘Performa Kalimat Anak pada Masa Konstruksi Sederhana: Studi Kasus terhadap Anak Usia 4 Tahun', Jurnal Obsesi : Jurnal Pendidikan Anak Usia Dini, 3(1), p. 191. doi: 10.31004/obsesi.v3i1.162.

Yunita, H., Meilanie, S. M. and Fahrurrozi, F. (2019) 'Meningkatkan Kemampuan Berpikir Kritis melalui Pendekatan Saintifik', Jurnal Obsesi : Jurnal Pendidikan Anak Usia Dini, 3(2), p. 425. doi: 10.31004/obsesi.v3i2.228. 